of the ion $R+$. The great increase in the ease of ionization of $R-X$ along this series is found to be due to the very marked decrease in the Ionization potential of the radical $R$ from methyl to tert.-butyl. The values of the ionization potentials of methyl and ethyl have been determined as 232 and 200 kcal. respectively'. The ionization potentials of the sec.-propyl and tert.-butyl radicals can be estimated from the results of electron impact experiments on $n$-propane, $n$-butane, isa-butane, $n$-propyl chloride and tert.-butyl chloride as about 179
and 165 kcal. respectively. This decrease of about $70 \mathrm{kcal}$. In the and 165 kcal. respectively. This decrease of about $70 \mathrm{kcal}$. In the main cause of the increase in the unimolecular reaction-rate of $R-X$
main main cause of the

The decrease in the bimolecular $S_{N^{2}}$ reaction-rate as $R-X$ changes from a primary to a tertiary halide has been attributed by Polanyi and co-workers to the increase in steric hindrance along this series $\mathrm{s}^{\mathbf{8} 4}$. Calculations of this steric hindrance have been made for the methyi to the tert.-butyl series ${ }^{\circ}$ and it has been found possible to account for the decrease in the bimolecular rate from $\mathrm{MeX} X$ to tert.-BuX in torms of carbon-halogen bond-strengths and steric hindrance.

corms of carbon-halogen bond-strengths and steric hindrance.
Strong evidence for the view that the decrease in the bimolecular rate from primary to tertiary halides is due to an increase in steric hindrance and not due to an increase in electron accession to the reactive carbon atom may be obtained by considering the reactions of allyl chloride and its $a$ - and $\gamma$-methyl derivatives. It is found that the unimolectlar rate sequence of these chlorides is $\gamma$-methylallyl $\approx \alpha$ methylallyl $>$ allyl ${ }^{10}$. The equivalence of the unimolecular reaction-
rates of the $\gamma$-methylallyl chloride and $\alpha$-methylallyl chloride would indicate that the electron-releasing capacity of the methyl group is transmitted with undiminished power to the seat of substitution ${ }^{10}$. The methyl group, therefore, should cause the same increase in electron accession to the reaction centre, whether it is in the $a$ - or the $\gamma$-position, and thus on the Hughes and Ingold theory one would expect the bimolecular $S_{X^{2}}$ reactions of these two halides to show the same rate. The observed bimolecular rate sequence, however, is $\gamma$-methylallyl $>$ allyl $>a$-methylallyl10. (Rate sequences similar to those given by Hughes have been obtained for the unimolecular and bimolecular reactions of $\alpha$-methylallyl and $\gamma$-methylallyl chlorides by Young and Andrews. ${ }^{12}$.) This bimolecular rate-sequence is in contradiction to that which would be expected on the Hughes and Ingold theory, and the only factor that can account for this marked difference between the unimolecular and the bimolecular rate sequences of these three halldes is the steric hindrance caused by the substituent methy of $\alpha$-methylallyl chloride but is absent both in the bimolecular $S_{N^{2}}$ reaction of $\gamma$-methylallyl chloride and in the unimolecular $S_{N^{1}}$ reactions of $a$ - and $\gamma$-methyllalyl chlorides. This is strong evidence for the conclusion that the decrease in the bimolecular reaction-rate as the reactive carbon atom changes from primary to secondary is due to an increase in steric hindrance, as suggested by Polanyi and coworkers, and not due to an increase in electron accession to the reactive carbon atom as postulated by Hughes and Ingold.

The bimolecular $S_{N^{2}}$ reaction-rate of $R-X$ decreases as $R$ changes The bimolecular $S_{N 2}$ reaction-rate of $R-\bar{X}$ decreases as $R$ changes
along the series ethyl, $n$-propyl, iso-butyl, neopenty ${ }^{10}$. Hughes has along the series ethyl, $n$-propyl, iso-butyl, neopentyl ${ }^{10}$. Hughes has may in principle enter in at all stages of $\beta$-substitution. but that it may in principle enter in at all stages of $\beta$-substitution, but that it We have estimated the steric hindrance for this series, and we attribute the decrease in rate of the bimolecular reaction along the whole of this series to the increase in steric hindrance as in the case of the methyl to tert.-butyl series.

Chemistry Department,

University of Manchester. Dec. 10.

${ }^{1}$ Ingold and Rothstein, J. Chem. Soc., 1217 (1928). Hughes, Ingold and Patel, J. Chem. Soc., 526 (1933). For further references see "General Discussion on Mechanism of Organic Reactions in Iiquid Systems", Trans. Farad. Soc., 37, 601 (1941).

Bateman and Hughes, J. Chem. Soc., 945 (1940).

- Bateman, Cooper, Hughes and Ingold, J. Chem. Soc., 925 (1940).

Ogg and Polany, Trans. Farad. Soc., 31,604 (1935).

Baughan, Evans, M. O., and Polanyi, Trans. Farad. Soc., 37, 377 (1941).

- Hipple and Stevenson, Phys. Rev., 63, 121 (1943)

Hipple and Stevenson, J. Amer. Chem. Soe., 64, 1590, 2766, 2768

: Meer and Polanyi, Z. phys. Chem., B, 19, 164 (1932).

i Evans, A. G., and Polanyi, Nature, 149,608

"1 Young and Andrews, J. Amer. Chem. Soc., 68, 421 (1944).

\section{An Isomeride of Abietic Acid}

DURING the course of a series of oil investigations, an oil loaded with resin was distilled in vacuo ( 28 in. mercury); subsequent to distillation the residue was found to contain a substance having the themical properties of abietic acid but which differed physically in chemical properties of abletic acid but which differed physically in actd. The different physical properties were discovered after purifica-

The compound in question is moderately soluble in alcohol and crystallized from such solution in the form of plates having a hexagonal periphery. The molecular weight was found to be 412 and it whe physical characteristics contrasted with normal abietic acid are:

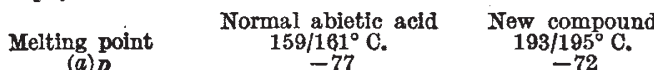

As in the case of normal abietic acid, it was easy to prepare a sodium salt from the new compound; circumstances prevented a check being made to ascertain whether the salts of the normal and new acids
possessed similar properties, but further work on this point is in hand.
It should be noticed that the fixed constants of this isomeride differed from those of the isomerides produced by heating abietio acid with acetic acid and hydrochloric acid.

A more detailed account is to be published shortly; in the meantime, I should be very pleased if anyone interested in terpene chemistry who has found similar reactions would take up the matter with m.

\section{Chemical Laboratory,}

Humber, Ltd.

Coventry.

'Steele, J. Amer. Chem. Soc., 1333 (1922); 1935 (1934).

\section{Quinoxaline and its Monohydrate}

Aumhodar quinoxaline, $\mathrm{C}_{8} \mathrm{H}_{8} \mathrm{~N}_{2}$, was synthesized in $1884^{1,2}$, and has been mentioned in the literature $\theta^{1-12}$ several times since that date, it is rather surprising that the existence of quinoxaline monohydrate has not been noticed, the more so since several physico-chemical determinations have boen carried out with quinoxaline; namely, vapour density in diphenylamine vapour ${ }^{3} ;$ density and refractive and use of quinoxaline as the cryoscopic solvent for the molecular and use estimation of naphthalene ${ }^{8}$

Recorded values for the melting point of quinoxaline have varied from $27^{\circ}$ to $32.0^{\circ}$ (corr.) $)^{\circ}$. It has now been found that quinoxaline as obtained by crystallization from light petroleum (b.p. $40-60^{\circ}$ ) or by distillation (b.p. $227-229^{\circ}$ ) is the anhydrous form with m.p. $28^{\circ}$ (found : $\mathrm{C}, 74.1 ; \mathrm{H}, 4.6 ; \mathrm{N}, 21 \cdot 4$; calc. for $\mathrm{C}_{8} \mathrm{H}_{4} \mathrm{~N}_{2}: \mathrm{C}, 73.8$ line is converted within a short time, depending on the humidity, into quinoxaline monohydrate with m.p. $37^{\circ}$ (found: C, 65.4; $\mathrm{H}, 5.4$; $\mathrm{N}, 18.8 ; \mathrm{C}_{8} \mathrm{H}_{6} \mathrm{~N}_{2} . \mathrm{H}_{2} \mathrm{O}$ requires $\mathrm{C}, 64 \cdot 9 ; \mathrm{H}, 5 \cdot 4 ; \mathrm{N}, 18 \cdot 9$ per cent). Occasionally the anhydrous quinoxaline is precipitated from light petroleum as an oil, but this readily solidifles on the addition of 8 petroleum as an oil, but trops of water to give quinoxaline monohydrate, m.p. $37^{\circ}$. The few drops of water to give quinoxaline monohydrate, m.p. 37 . The existence of the monohydrate is further proved by its behaviour on distillation, when water (identifled by its b.p. $100^{\circ}$, and ability to turn anhydrous copper sulphate blue) distils over first,

nhydrous quinoxaline, b.p. 227-229 and m.p. 28 . A further property of quinoxaline which has escaped mention in the literature is that of its volatility both in air at room tempersture and in the vapours of organic solvents at their boiling point; The example, $0.4 \mathrm{gm}$. quinoxaline distils over per litre of benzene. The quinoxaline can be removed from the distillate colour given with a drop of concentrated sulphuric acid or by the yellow precipitate given drop of concentrated sulphuric acid or by the yellow precipitate

with a benzene or petroleum solution of $2: 4$-dinitro phenol. In contrast to the interaction of quinoxaline and potassamide in liquid ammonia to give the dipotassium salt of fluorubin ${ }^{\circ}$, quinoxaline reacts with sodamide in dimethyl aniline at $210-225^{\circ}$ to give two products: 2 : $2^{\prime}$-diquinoxalyl, m.p. $274-276^{\circ}$ (found $\mathrm{C}, 74 \cdot 4 ; \mathrm{H}, 3 \cdot 9$; Maurer and Boettger ${ }^{16}$ obtained $2: 2^{\prime}$-diquinoxalyl from $o$-phenylene diamine and dihydro quinoxalyl glycolaldehyde and give m.p. $274^{\circ}$, and $2: 3$-dihydroxyquinoxaline, m.p. $386-390^{\circ}$ decomp. (found : N, $17 \cdot 3$ per cont. Motylewski ${ }^{13}$ gives m.p. $410^{\circ}$ for $2: 3$-dihydroxy quinoxaline obtained by oxidation of $1: 2$-dihydro-3-hydroxyquinoxaline). The identity of the 2:3-dihydroxyquinoxaline was also confirmed by its conversion to $2: 3$-dichloro quinoxaline, m.p. $147^{\circ}$ (Hinsberg and Pollak ${ }^{16}$ give m.p. $150^{\circ}$ )

Wellcome Laboratories of Tropical Medicine,

B. C. Platit. London, N.W.1. Dec. 20.

${ }^{2}$ Hinsberg, O., Ber. deut. chem. Ge8., 17, 320 (1884); Ann., 237, 334 (1887).

Koerner, W., Acc. dei Lincei, Trans., 8, 219 (1884)

Merz, V., and Ris, C. Ber. deut. chem. Qtes., 20, 1194 (1887).

- Brühl, J.'W., Z. phys. Chem., 22, 383 (1897); ibid., 79, 4 and 509 (1912) Gabriel, S., and Sonn, A., Ber. deut. chem. Ges., 40, 4851 (1907).

'Padoa, M., Atti Reale Acc. Lincei, 15], 12, I, 393 (1903).

Hinsberg, O., J. prakt. Chem., [2], 94, 182 (1916).

- Chattaway, E. D., and Humphrey, W. G., J. Chem. Soc., 648 (1829) Bergstrom, F. W., and Ogg, jun., R. A., J. Amer. Chem. Soc., 58, 246 (1931).

${ }^{10} \mathrm{Kuhn}, \mathrm{R} .$, and Bar, F., Ber. deut. chem. Ges., 67, 903 (1934).

1 Maurer, K., Schiedt, B., and Schroeter, H., Ber. deut. chem. Ges., 68,1721 ' (1935).

18 Sausville, J. W., and Spoerri, P. E., J. Amer. Chem. Soc., 63, 3153 (1941). (1944).

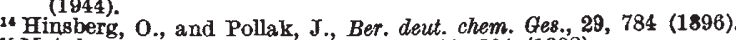
15 Motylewski, S., Ber. deut. chem. Ges., 41, 804 (1908)

is Maurer, K., and Boettger, B., Ber. deut. chem. Ges., 71, 2092 (1938).

\section{Antimalarial Action of Cinnoline Derivatives}

A NOTBwORTHY feature of the published synthetic work relevant to the chemotherapy of malaria is the extent to which attention has been concentrated on the preparation of active agents derived from either quinoline or acridine, of which the two outstanding examples are, respectively, pamaquin and mepacrine. By comparison, littl information is avatlable concerning the effectiveness of other structural types, with the important excepti

In an attempt to discover antimalarial activity in the quinazoline fleld, various 4-bassicalkylaminoquinazolines (formula $I ; R=N O$ or (1) were prepared by Magidson and Golovehinskaya but the 